\title{
Chemistry of CpG DNA
}

The innate immune system of vertebrates has evolved to recognize specific pathogenassociated molecular patterns (PAMPs) present in invading microorganisms through pattern recognition receptors (PRRs; Lien and Ingalls, 2002). One of several such PAMPs is the unmethylated $\mathrm{CpG}$ dinucleotide present in specific sequence contexts (CpG motifs) in pathogenic microorganisms (Hemmi et al., 2000). On sensing a $\mathrm{CpG}$ motif, PRRs trigger complex signal transduction pathways that ultimately activate a number of transcription factors, including NF- $\kappa \mathrm{B}$ and AP-1. These induce specific patterns of gene expression associated with the development and maintenance of immune responses. The immune responses to bacterial and synthetic oligonucleotides containing $\mathrm{CpG}$ motifs include proliferation of $\mathrm{B}$ cells, production of cytokines IL-12, $\gamma$-IFN, IL-6, and TNF- $\alpha$ (Klinman et al., 1996; Zhao et al., 1997), and production of costimulatory molecules by monocytes/macrophages, B cells, dendritic cells (DCs), and natural killer (NK) cells.

\section{HISTORY}

Tokunaga and coworkers were the first to report that DNA from Mycobacterium bovis induces production of interferons $\alpha, \beta$, and $\gamma$ (IFN- $\alpha,-\beta$, and $-\gamma$ ), augments NK cell activity, and shows antitumor activity (Tokunaga et al., 1984). The same authors, using short synthetic DNA fragments, showed that palindromic sequences containing $\mathrm{CpG}$ dinucleotides efficiently induce NK cell activity and induce IFNs (Yamamoto et al., 1992a). Subsequent studies demonstrated that bacterial DNA, but not mammalian DNA, induces murine B cell proliferation and cytokine secretion (Messina et al, 1991; Yamamoto et al., 1992b). Later studies showed that unmethylated $\mathrm{CpG}$ dinucleotides in specific sequence contexts present in bacterial DNA, synthetic oligodeoxyribonucleotides, and DNA vaccines are responsible for the observed immune responses (Krieg et al., 1995; Sato et al., 1996). Compared to bacterial DNA, the occurrence of CpG motifs in vertebrate DNA is sparse. In addition, the vertebrate $\mathrm{C}$ residues usually carry a 5-methyl substituent (Bird, 1986), which enables the immune system to distinguish between its own DNA and bacterial DNA that signals an infection.

\section{RECEPTORS}

The recognition of $\mathrm{CpG}$ DNA has been shown to occur through Toll-like receptor 9 (TLR9), which belongs to a family of proteins called TLRs (Hemmi et al., 2000). The TLRs function as PRRs to initiate the innate immune response against invading microorganisms. However, direct evidence for binding of $\mathrm{CpG}$ DNA to TLR9 has not yet been documented. Although most other TLRs are membrane receptors, growing evidence suggests that TLR9 is localized in the cytoplasm (Takeshita et al., 2001; Ahmad-Nejad et al., 2002). Therefore, cellular uptake and endosomal localization seem to be prerequisites for $\mathrm{CpG}$ DNA recognition (Stacey et al., 2000).

\section{Sequence and Structural Specificity of TLR9}

TLR9 proteins from different vertebrates vary in the $\mathrm{CpG}$ DNA sequences they recognize (Bauer et al., 2001a). Therefore, a CpG motif that is active in one species may not be in another. For example, mouse TLR9 prefers an unmethylated $\mathrm{CpG}$ dinucleotide flanked by two purine bases on the $5^{\prime}$ side and two pyrimidine bases on the 3' side, such as GACGTT (Krieg et al., 1995). CpG dinucleotides preceded by $\mathrm{C}$ or followed by $\mathrm{G}$ are generally less active in mice. Human immune cells respond optimally to GTCGTT or TTCGTT motifs (Hartmann et al., 2000). Certain other sequences, such as a palindromic AACGTT sequence, are known to induce immune responses in both mouse and human systems (Yamamoto et al., 1992a; Van Uden and Raz, 2000). Thus, TLR9 variants from different species recognize $\mathrm{CpG}$ dinucleotides flanked by a variety of sequences, though to different extents (Rankin et al., 2001; Zhang et al., 2001; Wernette et al., 2002).

\section{Signaling Events}

Though the evidence suggests that TLR9 is the receptor for phosphorothioate CpG DNAs, the role of TLR9 in mediating the observed effects of phosphodiester $\mathrm{CpG}$ oligonucleotides and bacterial DNA is not yet clear. The signaling events initiated by TLR9 in response to CpG DNA include recruitment of MyD88, IRAK, and TRAF6, which leads to activation of I $\mathrm{KB}$ kinase, MAP kinase, the stress kinases JNK-1 and -2, and p38, which in turn causes activation of transcription factors ATF-
Synthesis of Modified Oligonucleotides and Conjugates

4.16.1

Supplement 12 
2, AP-1, and NF- $\kappa B$ (Fig. 4.16.1). The activated transcription factors induce the synthesis of several regulatory cytokines and costimulatory molecules.

\section{SIGNIFICANCE OF CpG DINUCLEOTIDES AND CHEMISTRY OF CpG DNA}

A CpG dinucleotide present in specific sequence contexts is essential for immunostimulatory activity, whereas the inverted dimer, $\mathrm{GpC}$, is inactive. As discussed above, the flanking sequences play an important role in determining activity of CpG DNA (Yamamoto et al., 1992a; Krieg et al., 1995; Pisetsky, 1999). Recently, other structural features that influence the activity of synthetic oligonucleotides have been reported, including the nature of the internucleotide linkage, the nature and conformation of the sugar ring, modification or removal of nucleobases, accessibility of the $5^{\prime}$ end, and the nature and size of any $5^{\prime}$-terminal blocking group.

\section{DNA Backbone}

Shorter CpG DNA molecules with unmodified phosphodiester backbones may elicit potent immune stimulation in vitro (Sonehara et al., 1996; Iho et al., 1999). However, phosphorothioate-modified oligonucleotides are used more commonly to prevent rapid degradation by nucleases present in cells. Although phosphodiester and phosphorothioate $\mathrm{CpG}$ DNAs elicit superficially similar immune re- sponses, recent studies showed certain distinct differences in the actions of these two backbones (Ballas et al., 2001; Rothenfusser et al., 2001; Verthelyi et al., 2001, 2002; Dalpke et al., 2002; Gursel et al., 2002), which are not well understood (Fig. 4.16.2 and Table 4.16.1).

\section{Phosphodiester backbone}

Phosphodiester CpG DNAs containing palindromic structures and/or poly(dG) sequences effectively activate NK cells (Yamamoto et al., 1992a, 2000; Iho et al., 1999) and induce IFN- $\alpha / \beta$ production from plasmacytoid DCs (Bauer et al., 2001b; Kadowaki et al., 2001; Krug et al., 2001a,b). The effects of phosphodiester CpG DNAs are generally similar to those of bacterial DNA, and the induction of type I IFN is far greater than with phosphorothioate CpG DNAs. However, B cell activation by phosphodiester CpG DNA appears minimal compared with bacterial and phosphorothioate CpG DNAs. Phosphodiester CpG DNAs induce high levels of IFN- $\gamma$ and IL-12, but produce IL-6 only minimally. Phosphorothioate substitutions on either end of the phosphodiester CpG DNA improve resistance to nucleases (Dalpke et al., 2002). Incorporation of poly $(\mathrm{dG})$ sequences at the ends of the phosphodiester DNA has been reported to enhance nuclease stability and increase cellular uptake through scavenger receptors (Pearson et al., 1993; Kimura et al., 1994; Agrawal et al., 1996). CpG DNAs containing phosphorothioate poly $(\mathrm{dG})$ sequences at the $5^{\prime}$ and
Chemistry of CpG DNA

\subsection{2}

Supplement 12

Figure 4.16.1 The two members of the Toll-like receptor (TLR) family that recognize bacterial CpG DNA and double-stranded (ds) viral RNA. Key components involved in the signaling pathways are shown. The activated transcription factors ultimately upregulate the expression of a number of cytokines and costimulatory molecules. Abbreviations: AP-1, activator protein 1; ERK, extracellular-signal-regulated protein kinase; IкB, inhibitor of $\kappa \mathrm{B}$; IRAK, IL-1 receptor associated kinase; JNK, $c$-jun N-terminal kinase; MAPK, mitogen activated protein kinase; MyD88, myeloid differentiation

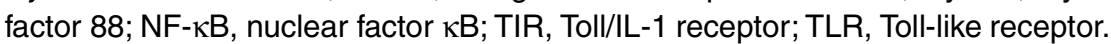

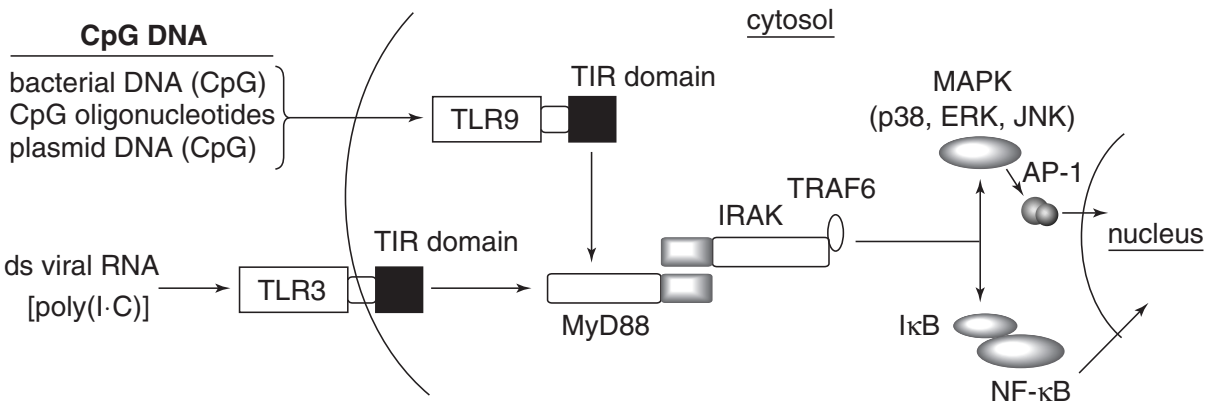




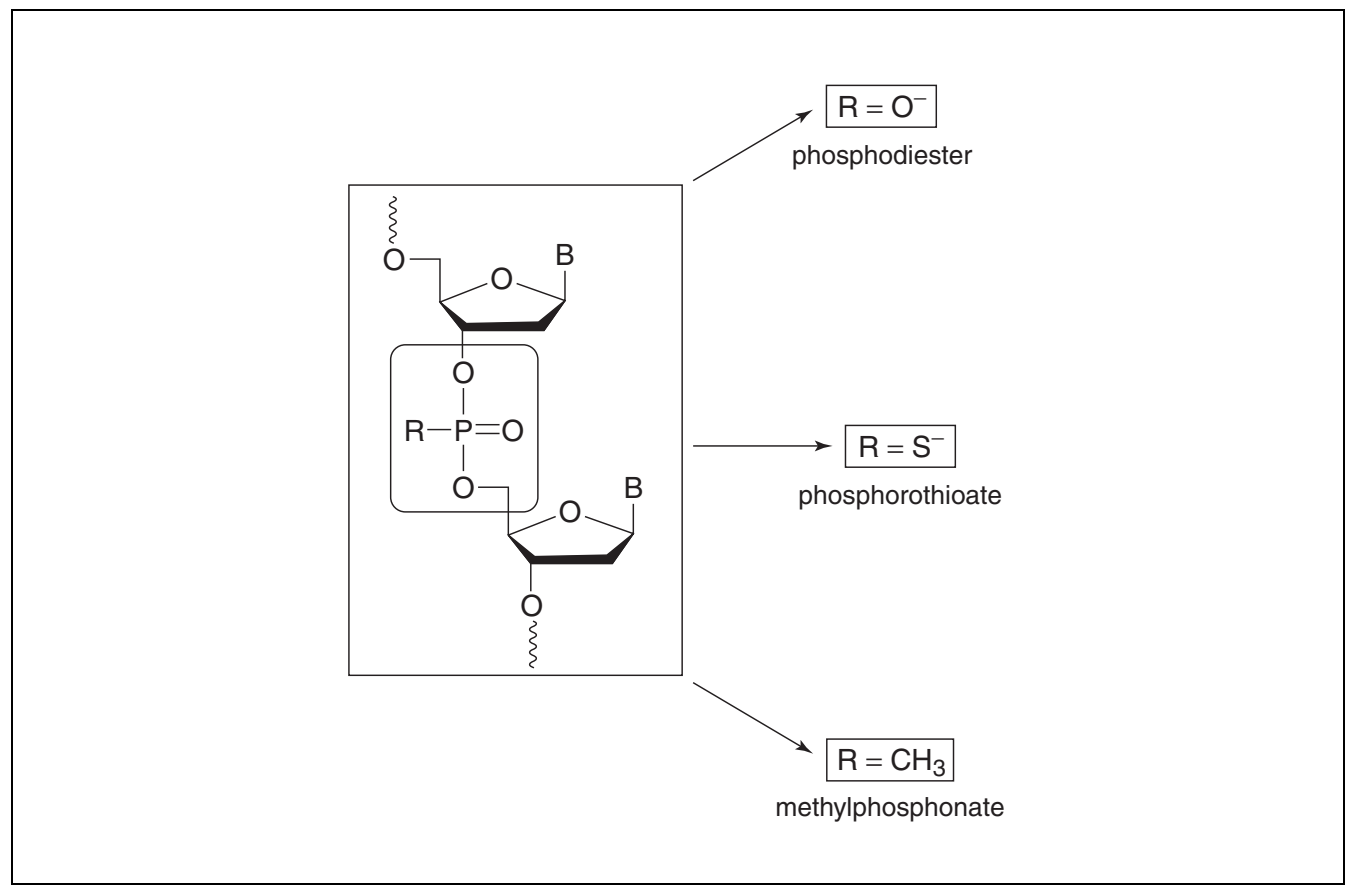

Figure 4.16.2 Chemical structure of a typical dinucleotide showing the internucleotide phosphate linkage (boxed) and the three backbone chemistries studied in CpG DNA for immunostimulatory activity. Some of the important immunostimulatory effects observed with each backbone modification are given in Table 4.16.2.

$3^{\prime}$ ends and a palindromic phosphodiester in the middle are potent adjuvants in vitro and in vivo (Dalpke et al., 2002; Verthelyi et al., 2002). However, it is unclear whether activity is due to the phosphodiester backbone, the poly $(\mathrm{dG})$ sequences, or secondary structures formed by palindromic and poly $(\mathrm{dG})$ sequences.

Recently, for the first time, the authors showed the use of phosphodiester CpG DNA without requiring palindromic structures and poly(dG) sequences for immunostimulatory activity (Yu et al., 2002a). For this study, two phosphodiester $\mathrm{CpG}$ oligodeoxynucleotides were attached via a glyceryl linker through their 3' ends. These $3^{\prime}-3^{\prime}$-linked CpG DNAs are referred to as immunomers. Phosphodiester immunomers showed remarkable stability against nucleases in medium containing $10 \%$ FBS that was not heat inactivated. Surprisingly, phosphodiester immunomers induced increased IL-12 secretion and minimal amounts of IL-6 secretion in mouse spleen cell cultures (Yu et al., 2002a). These studies suggest that it would be possible to modulate cytokine secretion profiles induced by $\mathrm{CpG}$ DNAs by using different backbone chemistries. In J774 cell cultures they activated NF- $\mathrm{KB}$ and induced cytokine secretion comparable to that of an unmodified 18-mer phosphorothioate CpG DNA containing the same $\mathrm{CpG}$ motif. Moreover, phosphodiester immunomers showed antitumor activity in nude mice bearing human breast (MCF-7) and prostate (DU145) cancer xenografts, suggesting that single-stranded phosphodiester CpG DNA can be a potent pharmacological agent.

\section{Phosphorothioate backbone}

In contrast, phosphorothioate CpG DNAs do not require palindromic sequences to induce immune responses. In general, phosphorothioate $\mathrm{CpG}$ oligonucleotides strongly stimulate B cell proliferation, as well as activate monocytes/macrophages, DCs, and B cells to produce cytokines and immunoglobulins (Branda et al., 1993; Krieg et al., 1995; Zhao et al., 1997; Stacey et al., 2000). Phosphorothioate $\mathrm{CpG}$ DNAs are the most extensively studied to date, and several are in clinical trials.

\section{Stereoenriched phosphorothioate backbone}

Substitution of a nonbridging oxygen with sulfur creates a chiral phosphorus center with $\mathrm{Rp}$ - and Sp-diastereomers. If there are $n$ phosphorothioate linkages in the backbone, conventional automated synthesis yields $2^{n}$ stereoisomers. Studies using stereoenriched all-Rp and all-Sp phosphorothioate CpG DNAs showed that the all-Rp analog induced lower cell pro-
Synthesis of Modified Oligonucleotides and Conjugates 
liferation than all-Sp or racemic CpG DNA analogs (Yu et al., 2000a). However, it is not clear if this is because of their differential susceptibility to nucleases (Tang et al., 1995; Yu et al., 2000a) or because one of the diastereomers is preferentially recognized by the receptor.

\section{Role of backbone charge and nonionic methylphosphonate linkages}

Substitution of a nonbridging oxygen on the internucleotide phosphate with a methyl group produces a nonionic phosphorus center (Fig. 4.16.2). Recent studies show that an uncharged methylphosphonate internucleotide linkage between $\mathrm{C}$ and $\mathrm{G}$ of the $\mathrm{CpG}$ dinucleotide diminishes the immune response (Zhao et al., 1996). Further, methylphosphonate substitutions within the three internucleotide linkages to the $5^{\prime}$-side of the $\mathrm{CpG}$ dinucleotide also suppress activity (Yu et al., 2001b). It appears that a negative charge on these internucleotide linkages is important for recognition and/or interaction between the CpG DNA and its receptor. Surprisingly, substituting the fifth or sixth linkage on the $5^{\prime}$ side of the $\mathrm{CpG}$ dinucleotide significantly enhances immunostimu-

Table 4.16.1 Properties of DNA Backbones with Different Linkages ${ }^{a}$

\begin{tabular}{|c|c|}
\hline Linkage & Property \\
\hline \multirow[t]{8}{*}{ Phosphodiester } & $\begin{array}{l}\text { Usually require longer length palindromic sequences to be stable } \\
\text { against nucleases }\end{array}$ \\
\hline & $\begin{array}{l}\text { May require higher concentrations to compensate for nuclease } \\
\text { degradation }\end{array}$ \\
\hline & Often require phosphorothioate-end modifications \\
\hline & Poly $(\mathrm{dG})$ end modifications are extensively used \\
\hline & $\begin{array}{l}\text { Produce high levels of IL-12, IFN- } \gamma \text {, and IFN- } \alpha / \beta \text {, and induce } \\
\text { minimal IL- } 6\end{array}$ \\
\hline & $\begin{array}{l}\text { Potent activators of NK and dendritic cells, but weak activators } \\
\text { of B cells }\end{array}$ \\
\hline & Produce TH1-type immune responses. \\
\hline & Potent adjuvants, and antitumor and antiasthmatic agents \\
\hline \multirow[t]{6}{*}{ Phosphorothioate } & Stable against nucleases \\
\hline & $\begin{array}{l}\text { Strong activators of B cells. Also directly activate } \\
\text { macrophages/monocytes and DCs, but do not directly activate } \\
\text { NK and T cells. }\end{array}$ \\
\hline & Produce a number of cytokines, including IL-12 \\
\hline & Produce Ig \\
\hline & Produce TH1 immune responses. \\
\hline & $\begin{array}{l}\text { Currently investigated for their potential in clinical trials as } \\
\text { anticancer, antiallergic, and antiinfectious agents }\end{array}$ \\
\hline \multirow[t]{6}{*}{ Methylphosphonate } & Only site-specific modifications have been studied \\
\hline & $\begin{array}{l}\mathrm{CH}_{3} \text { between } \mathrm{C} \text { and } \mathrm{G} \text { of the } \mathrm{CpG} \text { dinucleotide suppresses the } \\
\text { immune response }\end{array}$ \\
\hline & $\begin{array}{l}\mathrm{CH}_{3} \text { within three internucleotide linkages to } 5^{\prime} \text { of } \mathrm{CpG} \\
\text { suppresses the response }\end{array}$ \\
\hline & $\mathrm{CH}_{3}$ at five or six linkages from $5^{\prime}$ of $\mathrm{CpG}$ enhances the response \\
\hline & $\mathrm{CH}_{3}$ in $3^{\prime}$ flanking sequences has minimal effect \\
\hline & $\begin{array}{l}\text { May be possible to alter cytokine secretion by site-specific } \\
\text { incorporation of one or two linkages in CpG DNA }\end{array}$ \\
\hline
\end{tabular}

${ }^{a}$ Refer to Figure 4.16.2 for graphical depiction of the linkages. 
latory activity, which may reflect tighter binding to the receptor. In contrast, the presence of nonionic internucleotide linkages to the $3^{\prime}$ side of the $\mathrm{CpG}$ dinucleotide has an insignificant effect on activity.

\section{Sugar Modifications}

While TLR9 has been shown to be involved in CpG DNA immune activation, a closely related family member, TLR3, has been reported to specifically recognize viral and synthetic double-stranded RNA and induce immune responses (Alexopoulou et al., 2001). Ribose and deoxyribose sugar moieties adopt 2 '- and 3 '-endo conformations (Fig. 4.16.3) that attribute distinct structural, physicochemical, and biological properties to RNA and DNA, respectively. It appears that the vertebrate innate immune system has evolved to recognize both of these nucleic acid structures from invading microorganisms, but through different receptors (Fig. 4.16.1). The authors of this unit have extensively studied the effects of sugar modifications in CpG DNA, as discussed below.

\section{2'-Sugar modifications}

Replacing either nucleoside in the $\mathrm{CpG}$ dinucleotide with one that is modified at the 2 '-hydroxyl group ( $\mathrm{R}$ in Fig. 4.16.3A) impedes immunostimulatory activity (Zhao et al., 1996). However, $2^{\prime}$ - $O$-methyl- or $2^{\prime}$ - $O$-methoxyethylribonucleosides in the sequences flanking the CpG dinucleotide have different effects depending on the position of substitution (Zhao et al., 1999; 2000). In general, 2'-O-alkylribonucleosides adjacent to the $\mathrm{CpG}$ dinucleotide on the $5^{\prime}$ side impair activity, while the same substitution on the $3^{\prime}$ side has minimal effect. Importantly, activity increases when the substitutions are incorporated distal to the $\mathrm{CpG}$ dinucleotide on either side (Zhao et al., 1999, 2000; Agrawal and Kandimalla, 2001). Hence, the effects on receptor binding due to conformational changes within ribose are strongly dependent on the position of substitution relative to the $\mathrm{CpG}$ dinucleotide.

\section{3'-Sugar modifications}

The incorporation of unnatural $3^{\prime}$-deoxynucleosides results in the formation of $2^{\prime}-5^{\prime}$-inter-

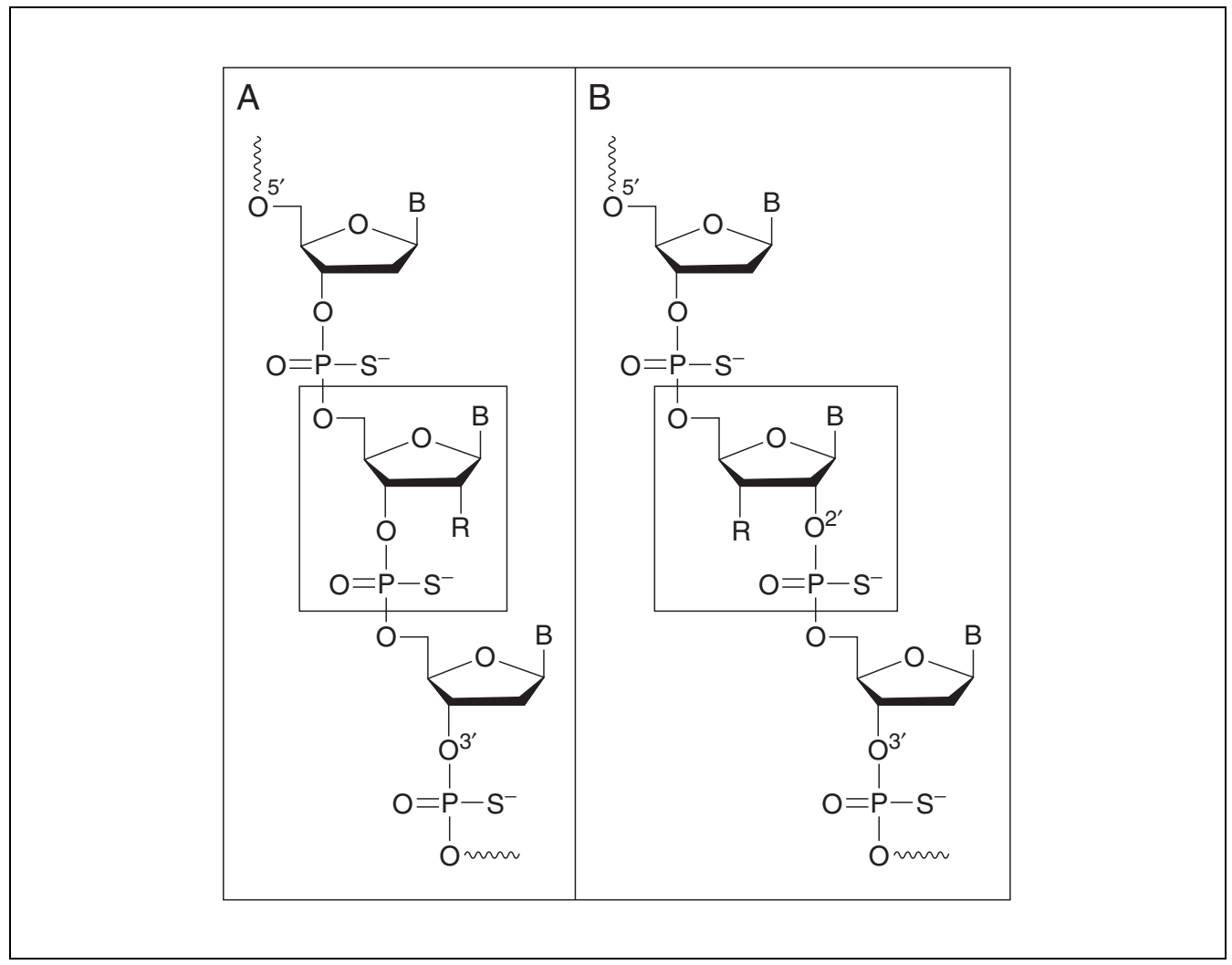

Figure 4.16.3 (A) Chemical structure of a DNA chain containing a single ribonucleoside (boxed). $\mathrm{R}$ is $-\mathrm{OH}$ (RNA), $-\mathrm{OCH}_{3}\left(2^{\prime}-\mathrm{O}\right.$-methyl RNA), or $-\mathrm{OCH}_{2} \mathrm{CH}_{2} \mathrm{OCH}_{3}\left(2^{\prime}-O\right.$-methoxyethyl RNA). (B) Chemical structure of a DNA chain with a $3^{\prime}$-deoxyribonucleoside $(\mathrm{R}=-\mathrm{H})$ or $3^{\prime}$-O-methylribonucleoside $\left(\mathrm{R}=-\mathrm{OCH}_{3}\right)$ (boxed). Note that the incorporation of a $3^{\prime}$-deoxy- or 3'-O-methylribonucleoside results in a $2^{\prime}-5^{\prime}$-linkage in an otherwise $3^{\prime}-5^{\prime}$-linked DNA.

Synthesis of Modified Oligonucleotides and Conjugates

\subsection{5}

Supplement 12 


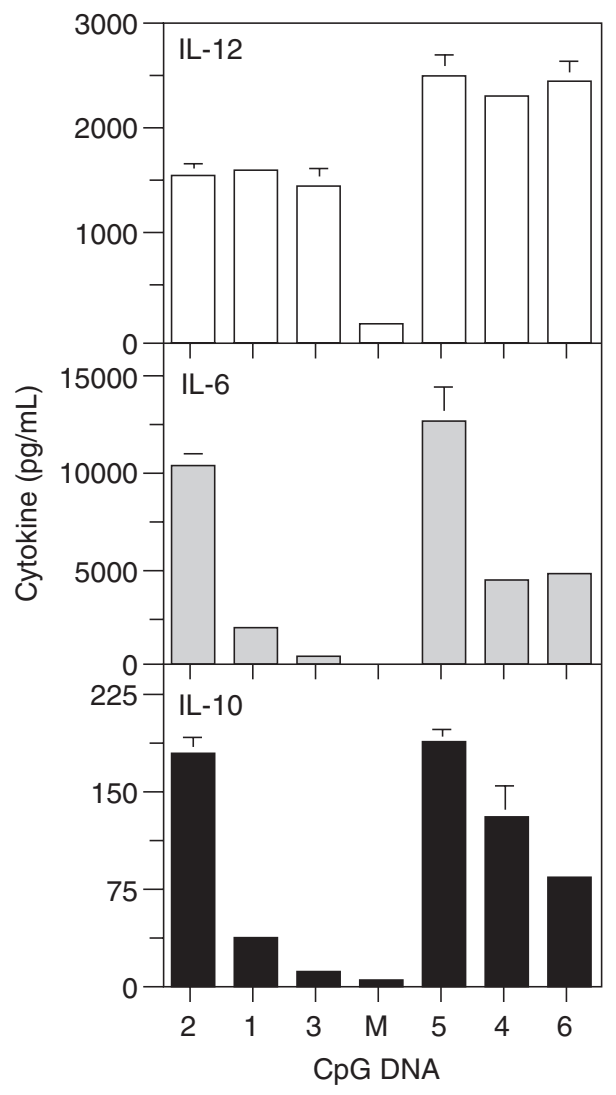

Figure 4.16.4 Effect of site-specific incorporation of a $3^{\prime}$-deoxyribonucleoside in different CpG DNA molecules ( 1 and 4 ) either in the $5^{\prime}$-flanking (2 and 5 ) or $3^{\prime}$-flanking sequence ( 3 and 6 ) on induction of cytokine (IL-12, -6 , and -10) secretion in BALB/c mouse spleen cell cultures. Data for specific compounds is taken from Yu et al. (2002c). BALB/c mouse spleen cell cultures were incubated for $24 \mathrm{hrs}$ with $1.0 \mu \mathrm{g} / \mathrm{mL}$ of CpG DNA. IL-12 secretion is not affected by either $5^{\prime}$ or $3^{\prime}$ modification. IL- 6 and -10 secretion is increased when the modification is in the $5^{\prime}$-flanking sequence and either decreased or unaffected when the modification is in the $3^{\prime}$-flanking sequence. $M$ is medium alone. Sequences of CpG DNA are: (1) 5'-d(CCTACTAGCGTTCTCATC)-3'; (2) 5'd(CCTAC ${ }^{\star}$ TAGCGTTCTCATC)-3'; (3) 5'-d(CCTACTAGCGTTCTC ${ }^{\star}$ ATC)-3'; (4) 5'-d(CTATCT GACG ITCTCTGT)-3'; (5) 5'-d(CTAT $C^{\star}$ TGACGTTCTCTGT)-3'; (6) 5'-d(CTATCTGACGTTCTC $C^{\star}$ TGT)-3'. $\mathrm{CpG}$ motifs are underlined. Italics indicate the $3^{\prime}$-deoxyribonucleosides. Asterisks indicate the position of the $2^{\prime}-5^{\prime}$-linkages.

nucleotide linkages in an otherwise $3^{\prime}-5^{\prime}$-linked DNA (Fig. 4.16.3B). The presence of a $3^{\prime}$-deoxynucleoside either within the $\mathrm{CpG}$ dinucleotide or adjacent to it abrogates immunostimulatory activity (Yu et al., 2002b). However, the same modification distal to the $\mathrm{CpG}$ dinucleotide in the $5^{\prime}$-flanking sequence potentiates activity. In the 3'-flanking sequence, 3'deoxynucleosides have an insignificant effect on immunostimulation. Interestingly, $3^{\prime}$-deoxynucleosides in either the $5^{\prime}$ - or the $3^{\prime}$-flanking sequence distal to the $\mathrm{CpG}$ dinucleotide result in different cytokine secretion profiles compared with unmodified CpG DNA (Fig. 4.16.4). It seems that changes in recognition and/or interaction with the receptor that are brought about by introducing chemical changes in CpG DNA are reflected in downstream events such as cytokine secretion. However, it is not clear yet if these distinct effects are a consequence of the differences in structural and/or kinetic interactions between the modified CpG DNA and its receptor. Nonetheless, by incorporating appropriate chemical modifications into CpG DNA, it may be possible to modulate cytokine secretion in a desirable fashion for specific disease indications. Similar effects have been reported with 3'-O-methylribonucleosides (Zhao et al., 2000; Agrawal and Kandimalla, 2001). 


\section{Significance of Deoxycytidine and Deoxyguanosine in CpG Dinucleotides: Synthetic Nucleosides}

Although flanking sequences strongly influence the interaction of CpG DNA and its receptors, the principal determinant in receptor recognition of a CpG DNA molecule (single- or double-stranded) is the unmethylated $\mathrm{CpG}$ dinucleotide itself. Any chemical modification introduced within the $\mathrm{CpG}$ dinucleotide that changes the DNA conformation - such as substitution of deoxyribose with ribose, $2^{\prime}-O$-substituted ribose, or $3^{\prime}$-deoxyribose, neutralization of the anionic phosphate charge between $\mathrm{C}$ and $\mathrm{G}$, or deletion of the $\mathrm{C}$ or $\mathrm{G}$ nucleobasecompletely abolishes recognition by the receptor and the subsequent immune responses. In addition, a methyl substitution at the 5 position of cytosine results in loss of activity (Zhao et al., 1996).

\section{Synthetic pyrimidines}

By replacing cytosine with synthetic pyrimidines, the authors have carried out an extensive study to delineate the importance for immunostimulation of each functional group on the pyrimidine ring of a $\mathrm{CpG}$ dinucleotide (Fig. 4.16.5). This study showed that deletion of any of the functional groups of cytosine (i.e., 2-keto, 3-imino, and 4-amino) resulted in loss of activity, suggesting that all three groups are important for recognition and/or interaction with the receptor (Kandimalla et al., 2001). Unlike a hydrophobic methyl group, a hydroxyl substituent at the 5 position of cytosine in $\mathrm{CpG}$ does not suppress immunostimulatory activity (Kandimalla et al., 2001). In addition, while the 4-amino group of cytosine is absolutely required, an alkyl substitution on the amino group does not interfere with recognition and subsequent activity (Kandimalla et al., 2001).

\section{Synthetic purines}

Similarly, a number of synthetic purine analogs substituted for guanine in a $\mathrm{CpG}$ dinucleotide have been studied (Fig. 4.16.6). Deletion or modification of functional groups at the 1,2 , and 6 positions result in the loss of immunostimulatory activity (Kandimalla et al., 2001). The deletion of nitrogen at the 7 position, however, does not, suggesting that N7 is not required for receptor recognition. These studies have provided important clues regarding the functional groups of guanine in a $\mathrm{CpG}$ dinucleotide that are required for recognition and/or binding to the receptor (Kandimalla et al., 2001). Importantly, these studies identified new, trademarked, synthetic dinucleotides (i.e., $\mathrm{YpG}, \mathrm{CpR}$, and $\mathrm{YpR}$, where $\mathrm{Y}$ and $\mathrm{R}$ are the synthetic pyrimidine and purine analogs in Figs. 4.16.5 and 4.16.6, respectively) that alter cytokine secretion profiles compared with the

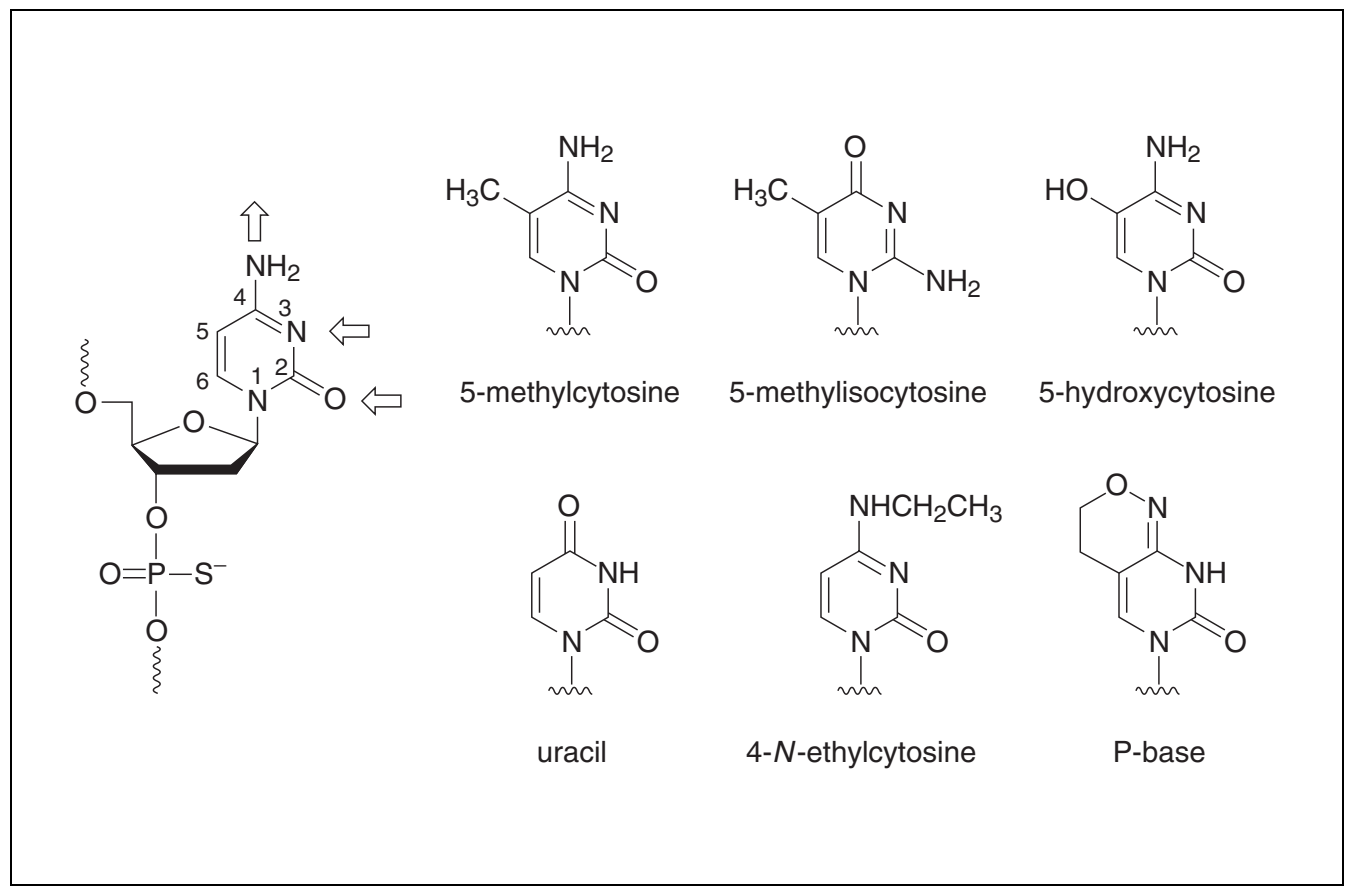

Figure 4.16.5 Structure of 2'-deoxycytidine showing hydrogen bond acceptor (inward arrows) and donor (outward arrow) groups on cytosine. Chemical structures of some of the synthetic pyrimidine analogs studied are shown.

Synthesis of Modified Oligonucleotides and Conjugates

\subsection{7}

Supplement 12 


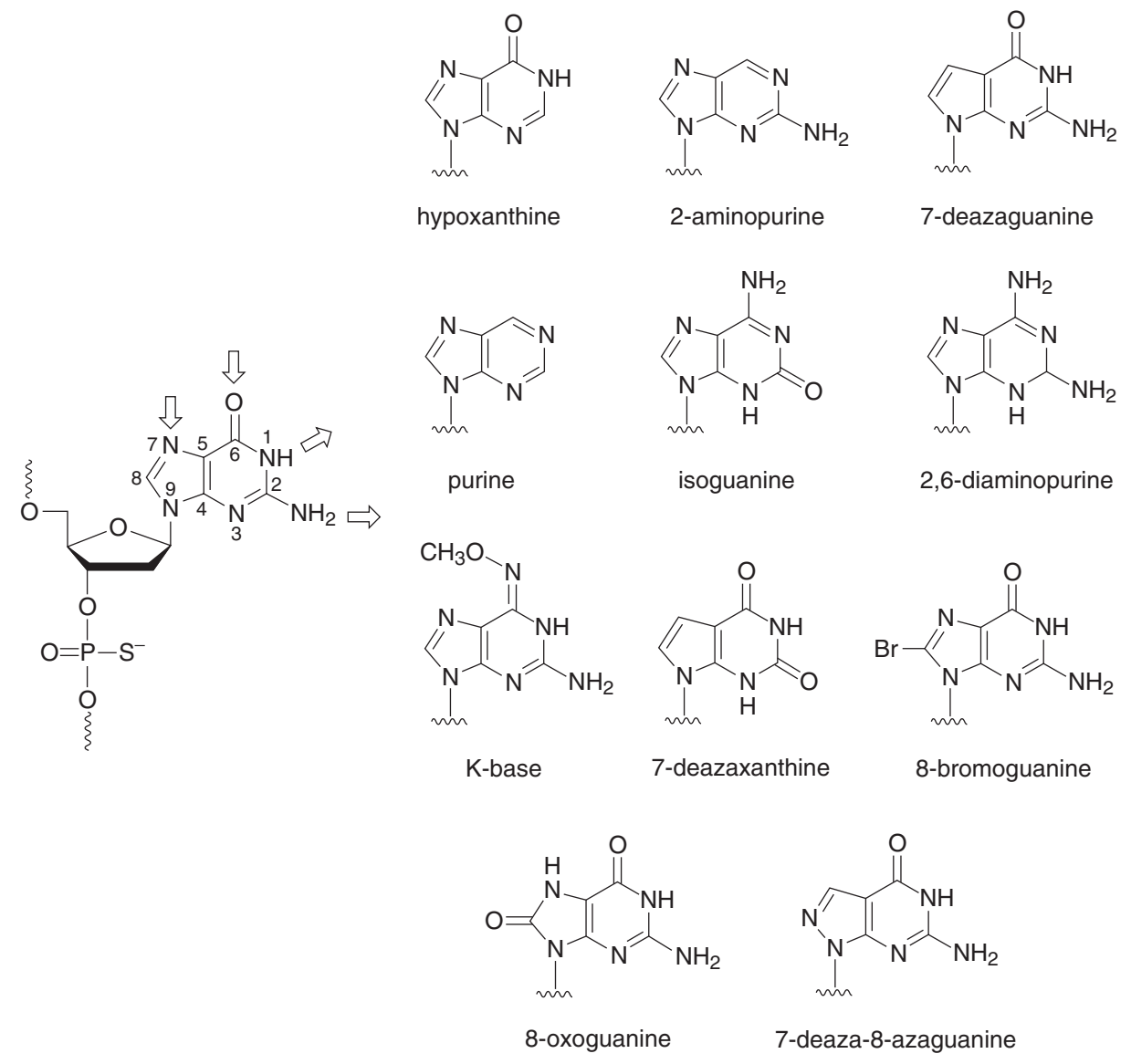

Figure 4.16.6 Structure of 2'-deoxyguanosine showing hydrogen bond acceptor (inward arrows) and donor (outward arrows) groups on guanine. Chemical structures of some of the synthetic purine analogs studied are shown.

natural $\mathrm{CpG}$ dinucleotide. Additionally, these studies indicate divergent synthetic nucleotide motif recognition patterns of the receptor and the possibility of modulating downstream cytokine secretion profiles using synthetic motifs placed appropriately in oligonucleotide sequences.

\section{Role of Nucleobases}

Recently, the need for each nucleobase in a CpG DNA for immune stimulation in mice by using abasic or 1',2'-dideoxynucleosides (Fig. 4.16.7A) has been reported. The presence of a nucleobase is absolutely required in both $\mathrm{C}$ and $\mathrm{G}$ positions of the $\mathrm{CpG}$ dinucleotide for activity. However, deletion of a nucleobase in the $5^{\prime}$-flanking region at a distance of three or more nucleosides from the $\mathrm{CpG}$ dinucleotide increases immunostimulatory activity (Yu et al., 2001a). A similar deletion in the 3 '-flanking sequence does not significantly affect activity, suggesting that not all nucleobases are involved in recognition. Possibly, nucleobases in certain positions cause steric hindrance when binding to the receptor. Deletion of one or two of them might relieve this strain, improving recognition and/or binding to the receptor. Moreover, nucleobase deletions in the $5^{\prime}$-flanking sequence increased IL-6 production compared with parent CpG DNA, while those in the $3^{\prime}$-flanking sequence had the opposite effect (Fig. 4.16.7B).

\section{Requirement of Nucleosides}

Recently it has been shown that non-nucleoside linkers (Fig. 4.16.8) could replace certain nucleosides in the $5^{\prime}$ - and 3 '-flanking sequences (Yu et al., 2002c). An alkyl linker in the flanking sequence $5^{\prime}$ to the $\mathrm{CpG}$ dinucleotide potenti-
Chemistry of CpG DNA

\subsection{8}




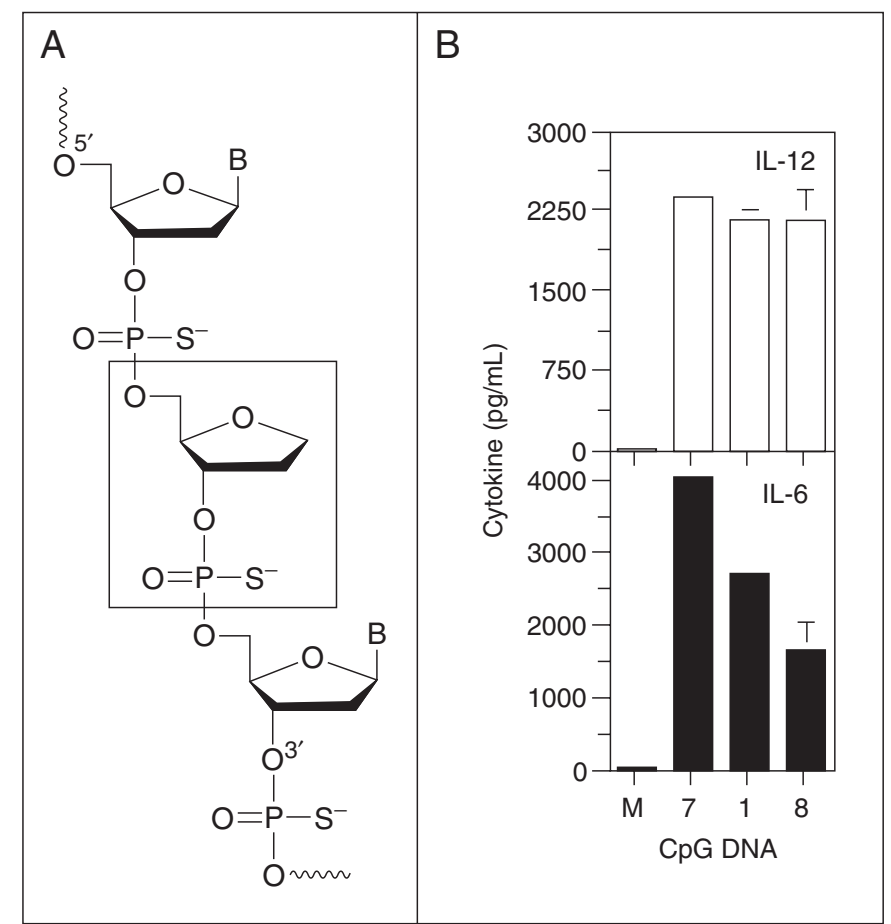

Figure 4.16.7 (A) Chemical structure of a DNA chain with a $1^{\prime}, 2^{\prime}$-dideoxyribonucleoside (boxed). $B$ indicates base. (B) Effect of site-specific incorporation of a $1^{\prime}, 2^{\prime}$-dideoxyribonucleoside in a CpG DNA molecule (1) in either in the $5^{\prime}$-flanking (7) or $3^{\prime}$-flanking (8) sequence on induction of cytokine (IL-12 and IL-6) secretion in BALB/c mouse spleen cell cultures. Data for specific compounds are taken from Yu et al. (2001a). BALB/c mouse spleen cell cultures were incubated for $24 \mathrm{hr}$ with 1.0 $\mu \mathrm{g} / \mathrm{mL}$ of CpG DNA. Note that IL-12 secretion is not affected by either $5^{\prime}$ or $3^{\prime}$ modification. IL-6 secretion is increased when the modification is in the $5^{\prime}$-flanking sequence and decreased when the modification is in the $3^{\prime}$-flanking sequence. $M$ is medium alone. Sequences of CpG DNAs are: (1) 5'-d(CCTACTAGCGTTCTCATC)-3'; (7) 5'-d(CCTXCTAGCGTTCTCATC)-3'; (8) 5'-d(CCTACTAGCGTTCXCATC)-3'. CpG motifs are underlined. $X$ indicates the position of $1^{\prime}, 2^{\prime}$-dideoxyribonucleoside.

ated immunostimulatory activity. Interestingly, the same substitution in the 3 '-flanking sequence did not affect immunostimulatory activity compared with parent CpG DNA. While a C3-linker optimally improved activity, longer ethyleneglycol and branched alkyl linkers (Fig. 4.16.8) were also beneficial. A linker in the 5 'flanking sequence increased IL-6 secretion several fold (Yu et al., 2002c). However, it is not clear whether the differences observed resulted from altered recognition/binding events with the receptor or initiation of different downstream signaling and transcriptional events compared with the parent CpG DNA.

\section{Accessibility to the $5^{\prime}$ End of CpG DNA is Required for Immunostimulatory Activity}

The findings discussed above clearly suggest that the sequence $5^{\prime}$ to the $\mathrm{CpG}$ dinucleotide plays a major role in immune stimulation, while that on the $3^{\prime}$ side has an insignificant effect. The authors' recent studies using $3^{\prime}-3^{\prime}$ - and 5'-5'-linked CpG DNAs suggest that an accessible $5^{\prime}$ end of $\mathrm{CpG}$ DNA is required for immunostimulatory activity (Yu et al., 2000 b). Increased activity is observed when two CpG DNAs are tethered through their 3' ends, while little or none is seen when they are tethered through their $5^{\prime}$ ends (Yu et al., 2000b).
Synthesis of Modified Oligonucleotides and Conjugates

4.16.9

Supplement 12 


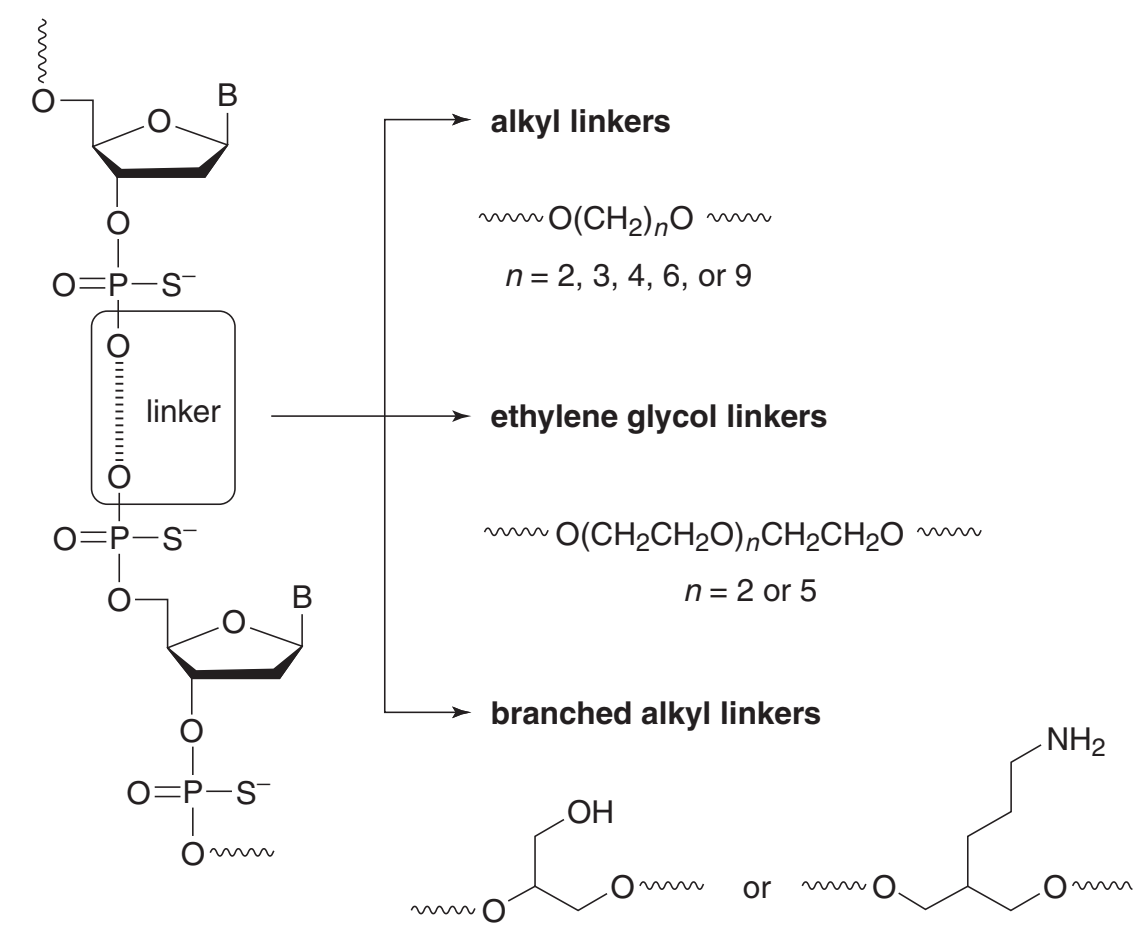

Figure 4.16.8 Chemical structure of a DNA chain containing an alkyl linker. Structures of various linkers studied are shown. B indicates base.

\section{Size of the 5'- or 3'-Attached Ligand Influences CpG DNA Activity}

Subsequent studies showed that accessibility at the $5^{\prime}$ end depends on the size of the ligand or moiety conjugated to this end of $\mathrm{CpG}$ DNA (Kandimalla et al., 2002). Conjugation of a small residue, such as a phosphorothioate group, at the $5^{\prime}$ end has an insignificant effect on immunostimulatory activity. However, conjugation of larger groups-including fluorescein, a mononucleotide, a tetramer, or a longer oligonucleotide $\left(5^{\prime}-5^{\prime}\right.$-linked $)$ - significantly interferes with activity. Surprisingly, conjugation of an oligonucleotide or a ligand to the $3^{\prime}$ end of CpG DNA (3'-3'-linked) has either an insignificant effect on activity or increases activity. Studies of cellular uptake and activation of transcription factor NF- $\mathrm{KB}$ in $\mathrm{J} 774$ cells using fluorescein-conjugated $\mathrm{CpG}$ DNAs suggest that both $5^{\prime}$ - and $3^{\prime}$-conjugates have similar cellular uptake, but only the $3^{\prime}$-conjugate activates NF- $\kappa \mathrm{B}$, not the $5^{\prime}$-conjugate.

CpG DNA has been shown to efficiently mediate antigen uptake and presentation by DCs only when antigen or allergen is conjugated to the CpG DNA (Shirota et al., 2000, 2001; Tighe et al., 2000a). CpG DNA conju- gates are currently in clinical trials for allergies (Tighe et al., 2000a,b; Horner et al., 2002). Routinely, ligands are conjugated to oligonucleotides at the $5^{\prime}$ end because of convenient synthetic protocols. However, the conjugation of a macromolecule or incorporation of G-rich sequences at the $5^{\prime}$ end could interfere with the recognition of the CpG DNA by its receptor, thereby reducing activity. The authors' studies suggest that the conjugation of functional ligands (e.g., antigen, antibody, allergen, another CpG DNA) at the $3^{\prime}$ end of CpG DNA not only contributes to increased stability against nuclease digestion but also increased immunostimulatory potency of $\mathrm{CpG}$ DNA in vivo.

\section{CONCLUSIONS}

CpGDNA is a powerful tool that can be used to modulate the immune system for treatment of a wide variety of disease indications. Several first-generation $\mathrm{CpG}$ DNA molecules are in clinical trials for a number of diseases either as monotherapies, in combination with antigens, vaccines, or monoclonal antibodies, or as conjugates with antigens (Gurunathan et al., 2000; Agrawal and Kandimalla, 2002; Kandimalla and Agrawal, 2002; Krieg, 2002). Extensive 
safety data is available from clinical studies of antisense oligonucleotides. Antisense oligonucleotides, which are used at several-fold higher concentrations than CpG DNA, have been administered to humans without serious adverse safety concerns. To date, several hundred people have been treated for up to two years without any evidence of anti-DNA antibody formation. Many of these molecules that are in clinical trials contain $\mathrm{CpG}$ dinucleotides. The presence of $\mathrm{CpG}$ dinucleotides in antisense oligonucleotides induces immune responses (Agrawal and Kandimalla, 2000; Lewis et al., 2000; Agrawal and Kandimalla, 2001; Jahrsdorfer et al., 2002), sometimes resulting in uncontrolled cytokine secretion, causing toxicity concerns (Agrawal and Zhao, 1998a,b; Agrawal, 1999a,b). A number of second-generation chemical modifications of $\mathrm{CpG}$ motifs in antisense oligonucleotides have been reported to suppress immune-related side effects (Agrawal and Zhao, 1998a,b; Agrawal, 1999a,b; Agrawal and Kandimalla, 2000).

The study of CpG DNA chemistry is a step closer towards understanding the biological effects and development of CpG DNA for human therapies. The chemical studies discussed in this review suggest that, in addition to the $\mathrm{CpG}$ dinucleotide, a number of other factors in $\mathrm{CpG}$ DNA molecules influence recognition by receptors, secretion of cytokines, and the resulting immunological effects. The ability to regulate cytokine induction through the use of second-generation $\mathrm{CpG}$ DNA modifications discussed in this review is an important factor in advancing the use of CpG DNA for specific disease indications with reduced toxicity concerns. Further understanding of the biological effects of second-generation CpG DNAs will lead to the design of more potent CpG DNA pharmacological agents.

\section{LITERATURE CITED}

Agrawal, S. 1999a. Factors affecting the specificity and mechanism of action of antisense oligonucleotides. Antisense Nucleic Drug Dev. 9:371375 .

Agrawal, S. 1999b. Importance of nucleotide sequence and chemical modifications of antisense oligonucleotides. Biochim. Biophys. Acta 1489:53-68.

Agrawal, S. and Kandimalla, E.R. 2000. Antisense therapeutics: Is it as simple as complementary base recognition? Mol. Med. Today 6:72-81.

Agrawal, S. and Kandimalla, E.R. 2001. Antisense and/or immunostimulatory oligonucleotide therapeutics. Current Cancer Drug Targets 1:197-209.
Agrawal, S. and Kandimalla, E.R. 2002. Medicinal chemistry and therapeutic potential of $\mathrm{CpG}$ DNA. Trends Mol. Med. 8:114-121.

Agrawal, S. and Zhao, Q. 1998a. Antisense therapeutics. Curr. Opin. Chem. Biol. 2:519-528.

Agrawal, S. and Zhao, Q. 1998b. Mixed backbone oligonucleotides: Improvement oligonucleotide-induced toxicity in vivo. Antisense $\mathrm{Nu}$ cleic Acid Drug Dev. 8:135-139.

Agrawal, S., Iadarola, P.L., Temsamani, J., Zhao, Q., and Shaw, D. 1996. Effect of G-rich sequences on the synthesis, purification, binding, cell uptake, and hemolytic activity of oligonucleotides. Bioorg. Med. Chem. Let. 6:2219-2224.

Ahmad-Nejad, P., Hacker, H., Rutz, M., Bauer, S., Vabulas, R.M., and Wagner, H. 2002. Bacterial CpG-DNA and lipopolysaccharides activate Toll-like receptors at distinct cellular compartments. Eur. J. Immunol. 32:1958-1968.

Alexopoulou, L., Holt, A.C., Medzhitov, R., and Flavell, R.A. 2001. Recognition of doublestranded RNA and activation of NF- $\kappa$ B by Tolllike receptor 3. Nature 413:732-738.

Ballas, Z.K., Krieg, A.M., Warren, T., Rasmussen, W., Davis, H.L., Waldschmidt, M., and Weiner, G.J. 2001. Divergent therapeutic and immunologic effects of oligodeoxynucleotides with distinct $\mathrm{CpG}$ motifs. J. Immunol. 167:48784886.

Bauer, S., Kirschning, C.J., Hacker, H., Redecke, V., Hausmann, S., Akira, S., Wagner, H., and Lipford, G.B. 2001a. Human TLR9 confers responsiveness to bacterial DNA via species-specific CpG motif recognition. Proc. Natl. Acad. Sci. U.S.A. 98:9237-9242.

Bauer, M., Redecke, V., Ellwart, J.W., Scherer, B., Kremer, J.P., Wagner, H., and Lipford, G.B. 2001b. Bacterial CpG-DNA triggers activation and maturation of human CD11c-, CD123+ dendritic cells. J. Immunol. 166:5000-5007.

Bird, A.P. 1986. CpG-rich islands and the function of DNA methylation. Nature 321:209-213.

Branda, R.F., Moore, A.L., Mathews, L., McCormack, J.J., and Zon, G. 1993. Immune stimulation by an antisense oligomer complementary to the rev gene of HIV-1. Biochem. Pharmacol. 45:2037-2043.

Dalpke, A.H., Zimmermann, S., Albrecht, I., and Heeg, K. 2002. Phosphodiester CpG oligonucleotides as adjuvants: Polyguanosine runs enhance cellular uptake and improve immunostimulative activity of phosphodiester $\mathrm{CpG}$ oligonucleotides in vitro and in vivo. Immunology 106:102-112.

Gursel, M., Verthelyi, D., Gursel, I., Ishii, K.J., and Klinman, D.M. 2002. Differential and competitive activation of human immune cells by distinct classes of $\mathrm{CpG}$ oligodeoxynucleotides. $J$. Leukoc. Biol. 71:813-820.

Gurunathan, S., Klinman, D.M., and Seder, R.A. 2000. DNA vaccines: Immunology, application, and optimization. Annu. Rev. Immunol. 18:927974.
Synthesis of Modified Oligonucleotides and Conjugates

4.16.11 
Hartmann, G., Weeratna, R.D., Ballas, Z.K., Payette, P., Blackwell, S., Suparto, I., Rasmussen, W.L., Waldschmidt, M., Sajuthi, D., Purcell, R.H., Davis, H.L., and Krieg, A.M. 2000. Delineation of a $\mathrm{CpG}$ phosphorothioate oligodeoxynucleotide for activating primate immune responses in vitro and in vivo. J. Immunol. 164:1617-1624.

Hemmi, H., Takeuchi, O., Kawai, T., Kaisho, T., Sato, S., Sanjo, H., Matsumoto, M., Hoshino, K., Wagner, H., Takeda, K., and Akira, S. 2000. A Toll-like receptor recognizes bacterial DNA. $\mathrm{Na}$ ture 408:740-745.

Horner, A.A., Takabaysahi, K., Zubeldia, J.M., and Raz, E. 2002. Immunostimulatory DNA-based therapeutics for experimental and clinical allergy. Allergy 57:24-29.

Iho, S., Yamamoto, T., Takahashi, T., and Yamamoto, S. 1999. Oligodeoxynucleotides containing palindrome sequences with internal $5^{\prime}-\mathrm{CpG}-3^{\prime}$ act directly on human $\mathrm{NK}$ and activated $\mathrm{T}$ cells to induce IFN- $\gamma$ production in vitro. J. Immunol. 163:3642-3652.

Jahrsdorfer, B., Jox, R., Muhlenhoff, L., Tschoep, K., Krug, A., Rothenfusser, S., Meinhardt, G., Emmerich, B., Endres, S., and Hartmann, G. 2002. Modulation of malignant B cell activation and apoptosis by bcl-2 antisense ODN and immunostimulatory CpG ODN. J. Leukoc. Biol. 72:83-92.

Kadowaki, N., Antonenko, S., and Liu, Y.J. 2001. Distinct $\mathrm{CpG}$ DNA and polyinosinic-polycytidylic acid double-stranded RNA, respectively, stimulate CD11 $\mathrm{c}^{-}$type 2 dendritic cell precursors and $\mathrm{CD} 11 \mathrm{c}^{+}$dendritic cells to produce type I IFN. J. Immunol. 166:2291-2295.

Kandimalla, E.R. and Agrawal, S. 2002. Towards optimal design of second-generation immunomodulatory oligonucleotides. Curr. Op. Mol. Ther. 4:122-129.

Kandimalla, E.R., Yu, D., Zhao, Q., and Agrawal, S. 2001. Effect of chemical modifications of cytosine and guanine in a CpG-motif of oligonucleotides: Structure-immunostimulatory activity relationships. Bioorg. Med. Chem. 9:807-813.

Kandimalla, E.R., Bhagat, L., Yu, D., Cong, Y., Tang, J., and Agrawal, S. 2002. Conjugation of ligands at the 5'-end of CpG DNA affects immunostimulatory activity. Bioconj. Chem. 13:966-974.

Kimura, Y., Sonehara, K., Kuramoto, E., Makino, T., Yamamoto, S., Yamamoto, T., Kataoka, T., and Tokunaga, T. 1994. Binding of oligoguanylate to scavenger receptors is required for oligonucleotides to augment NK cell activity and induce IFN. J. Biochem. 116:991-994.

Klinman, D.M., Yi, A.K., Beaucage, S.L., Conover, J., and Krieg, A.M. 1996. CpG motifs present in bacterial DNA rapidly induce lymphocytes to secrete interleukin 6, interleukin 12, and interferon $\gamma$. Proc. Natl. Acad. Sci. U.S.A. 93:28792883.

Krieg, A.M. 2002. CpG motifs in bacterial DNA and their immune effects. Annu. Rev. Immunol. 20:709-760.
Krieg, A.M., Yi, A.K., Matson, S., Waldschmidt, T.J., Bishop, G.A., Teasdale, R., Koretzky, G.A., and Klinman, D.M. 1995. CpG motifs in bacterial DNA trigger direct B-cell activation. Nature 374:546-549.

Krug, A., Rothenfusser, S., Hornung, V., Jahrsdorfer, B., Blackwell, S., Ballas, Z.K., Endres, S., Krieg, A.M., and Hartmann, G. 2001a. Identification of $\mathrm{CpG}$ oligonucleotide sequences with high induction of IFN- $\alpha / \beta$ in plasmacytoid dendritic cells. Eur. J. Immunol. 31:2154-2163.

Krug, A., Towarowski, A., Britsch, S., Rothenfusser, S., Hornung, V., Bals, R., Giese, T., Engelmann, H., Endres, S., Krieg, A.M., and Hartmann, G. 2001b. Toll-like receptor expression reveals CpG DNA as a unique microbial stimulus for plasmacytoid dendritic cells which synergizes with CD40 ligand to induce high amounts of IL-12. Eur. J. Immunol. 31:3026-3037.

Lewis, E.J., Agrawal, S., Bishop, J., Chadwick, J., Cristensen, N.D., Cuthill, S., Dunford, P., Field, A.K., Francis, J., Gibson, V., Greenham, A.K., Kelly, F., Kilkuskie, R., Kreider, J.W., Mills, J.S., Mulqueen, M., Roberts, N.A., Roberts, P., and Szymkowski, D.E. 2000. Non-specific antiviral activity of antisense molecules targeted to the E1 region of human papillomavirus. Antiviral Res. 48:187-196.

Lien, E., and Ingalls, R.R. 2002. Toll-like receptors. Crit. Care Med. 30:S1-S11.

Messina, J.P., Gilkeson, G.S., and Pisetsky, D.S. 1991. Stimulation of in vitro murine lymphocyte proliferation by bacterial DNA. J. Immunol. 147:1759-1764.

Pearson, A.M., Rich, A., and Krieger, M. 1993. Polynucleotide binding to macrophage scavenger receptors depends on the formation of basequartet-stabilized four-stranded helices. J. Biol. Chem. 268:3546-3554.

Pisetsky, D.S. 1999. The influence of base sequence on the immunostimulatory properties of DNA. Immunol. Res. 19:35-46.

Rankin, R., Pontarollo, R., Ioannou, X., Krieg, A.M., Hecker, R., Babiuk, L.A., and van den Hurk, S.v.d.L. 2001. CpG motif identification for veterinary and laboratory species demonstrates that sequence recognition is highly conserved. Antisense Nucleic Acid Drug Dev. 11:333-340.

Rothenfusser, S., Hornung, V., Krug, A., Towarowski, A., Krieg, A.M., Endres, S., and Hartmann, G. 2001. Distinct CpG oligonucleotide sequences activate human gamma delta $T$ cells via interferon- $\alpha /-\beta$. Eur. J. Immunol. 31:3525-3534.

Sato, Y., Roman, M., Tighe, H., Lee, D., Corr, M., Nguyen, M.D., Silverman, G.J., Lotz, M., Carson, D.A., and Raz, E. 1996. Immunostimulatory DNA sequences necessary for effective intradermal gene immunization. Science 273:352-354.
Chemistry of CpG DNA 4.16.12

Supplement 12 
Shirota, H., Sano, K., Kikuchi, T., Tamura, G., and Shirato, K. 2000. Regulation of murine airway eosinophilia and Th2 cells by antigen-conjugated $\mathrm{CpG}$ oligodeoxynucleotides as a novel antigen-specific immunomodulator. J. Immunol. 164:5575-5582.

Shirota, H., Sano, K., Hirasawa, N., Terui, T., Ohuchi, K., Hattori, T., Shirato, K., and Tamura, G. 2001. Novel roles of CpG oligodeoxynucleotides as a leader for the sampling and presentation of CpG-tagged antigen by dendritic cells. J. Immunol. 167:66-74.

Sonehara, K., Saito, H., Kuramoto, E., Yamamoto, S., Yamamoto, T., and Tokunaga, T. 1996. Hexamer palindromic oligonucleotides with $5^{\prime}$-CG$3^{\prime}$ motif(s) induce production of interferon. $J$. Interferon Cytokine Res. 16:799-803.

Stacey, K.J., Sester, D.P., Sweet, M.J., and Hume, D.A. 2000. Macrophage activation by immunostimulatory DNA. Curr. Top. Microbiol. Immunol. 247:41-58.

Takeshita, F., Leifer, C.A., Gursel, I., Ishii, K.J., Takeshita, S., Gursel, M., and Klinman, D.M. 2001. Role of Toll-like receptor 9 in CpG DNAinduced activation of human cells. J. Immunol. 167:3555-3558.

Tang, J.Y., Roskey, A.R., Li, Y., and Agrawal, S. 1995. Enzymatic synthesis of stereoregular (all $\mathrm{Rp}$ ) oligonucleotide phosphorothioate and its properties. Nucleosides Nucleotides 14:985989.

Tighe, H., Takabayashi, K., Schwartz, D., Van Nest, G., Tuck, S., Eiden, J.J., Kagey-Sobotka, A., Creticos, P.S., Lichtenstein, L.M., Spiegelberg, H.L., and Raz, E. 2000a. Conjugation of immunostimulatory DNA to the short ragweed allergen amb a 1 enhances its immunogenicity and reduces its allergenicity. J. Allergy Clin. Immunol. 106:124-134.

Tighe, H., Takabayashi, K., Schwartz, D., Marsden, R., Beck, L., Corbeil, J., Richman, D.D., Eiden, J.J. Jr., Spiegelberg, H.L., and Raz, E. 2000b. Conjugation of protein to immunostimulatory DNA results in a rapid, long-lasting and potent induction of cell-mediated and humoral immunity. Eur. J. Immunol. 30:1939-1947.

Tokunaga, T., Yamamoto, H., Shimada, S., Abe, H., Fukuda, T., Fujisawa, Y., Furutani, Y., Yano, O., Kataoka, T., Sudo, T., Makiguchi, N., and Suganuma, T. 1984. Antitumor activity of deoxyribonucleic acid fraction from Mycobacterium bovis BCG. I. Isolation, physicochemical characterization, and antitumor activity. J. Natl. Cancer Inst. 72:955-962.

Van Uden, J., and Raz, E. 2000. Introduction to immunostimulatory DNA sequences. Springer Semin. Immunopathol. 22:1-9.

Verthelyi, D., Ishii, K., Gursel, M., Takeshita, F., and Klinman, D. 2001. Human peripheral blood cells differentially recognize and respond to two distinct CpG motifs. J. Immunol. 166:2372-2377.
Verthelyi, D., Kenney, R.T., Seder, R.A., Gam, A.A., Friedag, B., and Klinman, D.M. 2002. CpG oligodeoxynucleotides as vaccine adjuvants in primates. J. Immunol. 168:1659-1663.

Wernette, C.M., Smith, B.F., Barksdale, Z.L., Hecker, R., and Baker, H.J. 2002. CpG oligodeoxynucleotides stimulate canine and feline immune cell proliferation. Vet. Immunol. Immunopathol. 84:223-236.

Yamamoto, S., Yamamoto, T., Kataoka, T., Kuramoto, E., Yano, O., and Tokunaga, T. 1992a. Unique palindromic sequences in synthetic oligonucleotides are required to induce INF and augment INF-mediated natural killer activity. $J$. Immunol. 148:4072-4076.

Yamamoto, S., Yamamoto, T., Shimada, S., Kuramoto, E., Yano, O., Kataoka, T., and Tokunaga, T. 1992b. DNA from bacteria, but not from vertebrates, induces interferons, activates natural killer cells and inhibits tumor growth. Microbiol. Immunol. 36:983-997.

Yamamoto, S., Yamamoto, T., Iho, S., and Tokunaga, T. 2000. Activation of NK cell (human and mouse) by immunostimulatory DNA sequence. Springer Semin. Immunopathol. 22:35-43.

Yu, D., Kandimalla, E.R., Roskey, A., Zhao, Q., Chen, L., Chen, J., and Agrawal, S. 2000a. Stereo-enriched phosphorothioate oligodeoxynucleotides: Synthesis, biophysical and biological properties. Bioorg. Med. Chem. 8:275-284.

Yu, D., Zhao, Q., Kandimalla, E.R., and Agrawal, S. 2000b. Accessible 5'-end of CpG-containing phosphorothioate oligodeoxynucleotides is essential for immunostimulatory activity. Bioorg. Med. Chem. Lett. 10:2585-2588.

Yu, D., Kandimalla, E.R., Zhao, Q., Cong, Y., and Agrawal, S. 2001a. Modulation of immunostimulatory activity of $\mathrm{CpG}$ oligonucleotides by site-specific deletion of nucleobases. Bioorg. Med. Chem. Lett. 11:2263-2267.

Yu, D., Kandimalla, E.R., Zhao, Q., Cong, Y., and Agrawal, S. 2001b. Immunostimulatory activity of $\mathrm{CpG}$ oligonucleotides containing non-ionic methylphosphonate linkages. Bioorg. Med. Chem. 9:2803-2808.

Yu, D., Zhu, F.G., Bhagat, L., Wang, H., Kandimalla, E.R., Zhang, R., and Agrawal, S. 2002a. Potent $\mathrm{CpG}$ oligonucleotides containing phosphodiester linkages: In vitro and in vivo immunostimulatory properties. Biochem. Biophys. Res. Commun. 297:83-90.

Yu, D., Kandimalla, E.R., Zhao, Q., Cong, Y., and Agrawal, S. 2002b. Immunostimulatory properties of phosphorothioate CpG DNA containing both $3^{\prime}-5^{\prime}$ - and $2^{\prime}-5^{\prime}$-internucleotide linkages. Nucl. Acids Res. 30:1613-1619.

Yu, D., Kandimalla, E.R., Cong, Y., Tang, J., Tang, J.Y., Zhao, Q., and Agrawal, S. 2002c. Design, synthesis, and immunostimulatory properties of CpG DNAs containing alkyl-linker substitutions: Role of nucleosides in the flanking sequences. J. Med. Chem. 45:4540-4548.
Synthesis of Modified Oligonucleotides and Conjugates

4.16.13

Supplement 12 
Zhang, Y., Shoda, L.K., Brayton, K.A., Estes, D.M., Palmer, G.H., and Brown, W.C. 2001. Induction of interleukin- 6 and interleukin-12 in bovine B lymphocytes, monocytes, and macrophages by a CpG oligodeoxynucleotide (ODN 2059) containing the GTCGTT motif. J. Interferon Cytokine Res. 21:871-881.

Zhao, Q., Temsamani, J., Iadarola, P.L., Jiang, Z., and Agrawal, S. 1996. Effect of different chemically modified oligodeoxynucleotides on immune stimulation. Biochem. Pharmacol. 51:173-182.

Zhao, Q., Temsamani, J., Zhou, R.Z., and Agrawal, S. 1997. Pattern and kinetics of cytokine production following administration of phosphorothioate oligonucleotides in mice. Antisense Nucleic Acid Drug. Dev. 7:495-502.
Zhao, Q., Yu, D., and Agrawal, S. 1999. Site of chemical modifications in $\mathrm{CpG}$ containing phosphorothioate oligodeoxynucleotide modulates its immunostimulatory activity. Bioorg. Med. Chem. Lett. 9:3453-3458.

Zhao, Q., Yu, D., and Agrawal, S. 2000. Immunostimulatory activity of $\mathrm{CpG}$ containing phosphorothioate oligodeoxynucleotide is modulated by modification of a single deoxynucleoside. Bioorg. Med. Chem. Lett. 10:1051-1054.

Contributed by Ekambar R. Kandimalla and Sudhir Agrawal

Hybridon, Inc.

Cambridge, Massachusetts 